This paper was presented in the 15th International Conference on Developments in Power System Protection (DPSP), Liverpool, United Kingdom, 2020. The following is a pre-print version of the paper.

Please cite this work as,

M. T. Hoq, J. Wang and N. Taylor, "Impact of High Levels of Series Compensation on Line Distance Protection," in the 15th International Conference on Developments in Power System Protection (DPSP), Liverpool, United Kingdom, 2020. 


\title{
IMPACT OF HIGH LEVELS OF SERIES COMPENSATION ON LINE DISTANCE PROTECTION
}

\author{
Md Tanbhir Hoq ${ }^{1 *}$, Jianping Wang ${ }^{2}$, Nathaniel Taylor ${ }^{1}$ \\ ${ }^{I}$ Division of Electromagnetic Engineering, KTH Royal Institute of Technology, Stockholm, Sweden \\ ${ }^{2}$ ABB Power Grids Sweden AB, Power Grids Research, Västerås, Sweden \\ *hoq@kth.se
}

Keywords: SERIES COMPENSATION, TRANSMISSION LINE, DISTANCE PROTECTION

\begin{abstract}
Series compensation of transmission lines creates several challenges for distance protection, particularly at the high compensation levels that have recently become more common. In this paper, the effect of high levels of series compensation on distance protection is evaluated, using a PSCAD simulation model of a $500 \mathrm{kV}, 200 \mathrm{~km}$ transmission line with a series capacitor bank. The capacitor bank model includes overvoltage protection using a metal oxide varistor (MOV) and bypass circuit breaker. Compensation levels of 70\%, 100\% and 140\% are simulated and phase to ground faults are simulated at several positions along the line, with fault resistance of $0 \Omega$ and $30 \Omega$ and fault inception angle of $0^{\circ}$ and $90^{\circ}$. It is observed from the simulation results that traditional distance protection experiences severe challenges at high levels of series compensation. With increasing compensation level, an increased length of line experiences voltage inversion and current inversion during a fault. The fault trajectories in the R-X plane show that voltage and current inversion during a fault can cause directional problems and delay for the distance relay. Sub-synchronous oscillation (SSO) is observed for faults in series compensated lines, causing over-reach and under-reach problems as well as delayed relay operation.
\end{abstract}

\section{Introduction}

Series capacitor compensation of a transmission line is done by connecting a capacitor in series with the line. The capacitor's reactance reduces the total inductive reactance of the compensated line, allowing more power transmission. The compensation level of the series capacitor is defined as the proportion of the line's inductive reactance that it compensates. If $X_{C}$ and $X_{L}$ are the reactance of series capacitor and the line, then compensation level $k$ is expressed as below in (1). In various series capacitor compensation projects around the world, compensation levels below $70 \%$ are common [1], [2].

$$
k=\frac{X_{C}}{X_{L}} \times 100 \%
$$

\subsection{Motivation}

Distance protection has been the most widely used protection scheme for transmission lines [3]. However, using series capacitors creates problems for distance protection during faults. A metal oxide varistor (MOV) is used to protect the capacitor from overvoltage when high fault currents flow in the line. The MOV starts conducting current during a fault, and depending on the fault condition it may eventually remove the capacitor from the fault loop. Non-linear behaviour of the MOV poses challenges for distance relays. Additionally, three special phenomena are observed that create further problems for distance protection. These are current inversion, voltage inversion and sub-synchronous oscillation (SSO). Current inversion occurs when the impedance from the source point to the fault becomes capacitive. The fault current thus becomes capacitive, strongly out of phase from the pre-fault angle.
Voltage inversion occurs if the line impedance from the measurement point to the fault becomes capacitive while the impedance between the source and fault remains inductive. During voltage inversion, the phase angle of the current roughly remains the same as its pre-fault value, but the phase of the voltage changes and lags the current. Voltage and current inversion can cause over-reach/under-reach, delays and directional problems for the distance relay. A fault or switching operation in a series compensated line will cause transient oscillations [2]. These low-frequency oscillations are called sub-synchronous oscillation (SSO), a term that is used here in this field even for frequencies somewhat higher than the synchronous frequency. SSO increases the operating time of distance protection and may cause overreach/under reach of the distance protection zones.

Previous research works have demonstrated the influence of series capacitors on distance protection [4]-[6]. However, those mainly concentrate on compensation levels of $50 \%$ or lower. In the last few years, higher compensation levels are being required and used in transmission lines for supplying more power to meet increasing demand. Higher compensation levels change how the series capacitor affects distance protection. Hence there is a need to study its effect on the transmission line distance protection.

\subsection{Objective}

The objective of this work is first to understand how a higher level of series capacitor compensation influences voltage inversion, current inversion and SSO, and second to 
investigate how different factors in series compensated lines affect the performance of distance protection.

\subsection{Paper Organization}

The rest of the paper is organized as follows. Section 2 describes the methodology behind the simulation setup. Section 3 presents simulation results and discussion divided into four subsections: MOV operation during a fault (3.1); current and voltage inversion (3.2); the effect of SSO (3.3); and the effect of these three phenomena on distance protection (3.4). Section 4 gives concluding remarks and considers future work.

\section{Methodology}

The conditions that cause current inversion, voltage inversion and SSO need to be explained briefly before discussing the simulation parameters. In Figure $1, X_{C}, X_{L}$ and $X_{S}$ are the reactance of the series capacitor, line and source. The fault occurs at $p \%$ of the line length from the source. For simplicity, let us assume that the capacitor is located in the sending bus and that we can find the line reactance during a fault by simply multiplying the total line reactance by $p$. The distance relay, current transformer (CT), voltage transformer (VT) and circuit breaker are located at the sending bus as shown in Figure 1.

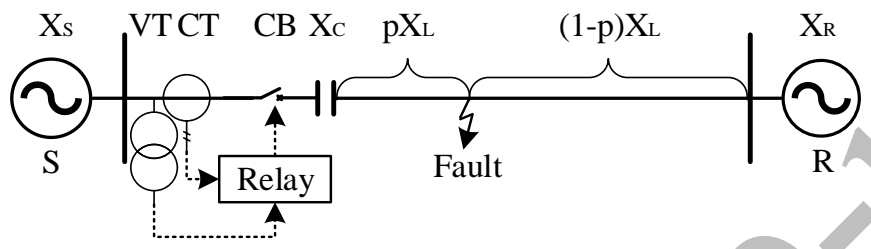

Figure 1 Line diagram of the simulation model

Current inversion will occur when the capacitive reactance is higher than the sum of the source and line reactance during a fault $\left(X_{C}>p X_{L}+X_{S}\right)$. Current inversion most easily occurs for faults close to the sending end (small value of $p$ ). Voltage inversion will occur when the capacitor's reactance is greater than the line reactance but smaller than the sum of line and source reactances $\left(p X_{L}+X_{S}>X_{C}>p X_{L}\right)$. From the conditions for voltage and current inversion, we can identify that they will not happen at the same time; voltage inversion occurs further away from the sending end than current inversion. Oscillations can occur because the series capacitor together with the transmission line creates a resonant resistive-inductivecapacitive circuit. The resonant frequency $\left(f_{r}\right)$ for a resonant circuit is expressed by (2). In (2), if $X_{C}>\left(p X_{L}+X_{S}\right)$ the resonant frequency is higher than the synchronous frequency, and if $X_{C}<\left(p X_{L}+X_{S}\right)$ the resonant frequency is lower than synchronous frequency. As mentioned before, subsynchronous frequency oscillation is problematic for distance protection: from (2) we can calculate the line segment where a fault would produce SSO close to $50 \mathrm{~Hz}$. From the conditions of voltage inversion and SSO, it can be observed that they can occur simultaneously.

$$
f_{n}=\frac{1}{2 \pi \sqrt{L C}}=f \sqrt{\frac{X_{C}}{X_{S}+p X_{L}}}
$$

Considering the background presented in the paragraph above, we can discuss how to set up simulations to observe current inversion, voltage inversion and SSO with higher compensation levels. All of these conditions are dependent on the source $\left(X_{S}\right)$, capacitor $\left(X_{C}\right)$ and line reactance during a fault $\left(p X_{L}\right)$. For simplicity, we can assume source reactance is fixed in all cases. As the goal is to study high levels of series compensation, three levels of series compensation are tested, compensating $70 \%, 100 \%$ and $140 \%$ of the line reactance. The transmission line reactance is also fixed, but the fault loop reactance depends on fault types, fault locations and fault impedances. Phase-ground faults are simulated, as they are the most common type of faults in transmission lines. Three fault locations are chosen for presenting the simulation results: 10 $\mathrm{km}, 100 \mathrm{~km}$ and $190 \mathrm{~km}$ from the sending bus. Depending on the compensation levels and fault location, current inversion, voltage inversion and/or SSO are observed. Then, to study the influence of other important parameters, fault resistance values of $0 \Omega$ and $30 \Omega$ and fault inception angles of $0^{\circ}$ and $90^{\circ}$ degree were used. The scenarios presented in the results are shown in Table 1. The source and line configurations used in the model are shown in Table 2 .

Table 1 Scenarios considered for simulation

\begin{tabular}{cccccc}
$\begin{array}{c}\text { Compensation } \\
\text { Level }\end{array}$ & $\begin{array}{c}\text { Fault Position } \\
(\mathrm{km})\end{array}$ & $\begin{array}{c}\text { Fault } \\
\text { Resistance } \\
(\Omega)\end{array}$ & $\begin{array}{c}\text { Fault } \\
\text { Angle } \\
\left({ }^{\circ}\right)\end{array}$ \\
$70 \%$ & 10 & 100 & 190 & $\begin{array}{c}0 \\
30\end{array}$ & $\begin{array}{c}90 \\
0\end{array}$ \\
$100 \%$ & 10 & 100 & 190 & $\begin{array}{c}30 \\
0\end{array}$ & 90 \\
$140 \%$ & 10 & 100 & 190 & 30 & 90 \\
\hline
\end{tabular}

Table 2: Source and tranmission line parameters

$\begin{array}{cc}\begin{array}{c}\text { Voltage } \\ (\mathrm{kV})\end{array} & \text { Positive } \\ & \text { Sequence } \\ \text { Impedance }(\Omega)\end{array}$

Zero Sequence Impedance $(\Omega)$

\begin{tabular}{cccc}
\hline $\begin{array}{c}\text { Sending } \\
\text { end }\end{array}$ & $510 \angle 25^{\circ}$ & $12 \angle 88^{\circ}$ & $36 \angle 80^{\circ}$ \\
$\begin{array}{c}\text { Receiving } \\
\text { end }\end{array}$ & $500 \angle-15^{\circ}$ & $100 \angle 80^{\circ}$ & $250 \angle 80^{\circ}$ \\
Line & - & $67.82 \angle 87.09^{\circ}$ & $210.16 \angle 75.63^{\circ}$ \\
\hline
\end{tabular}

The simulation model is built in PSCAD. The instantaneous values of current and voltage are exported from PSCAD to Matlab, for a simulated time of $1 \mathrm{~s}$ within which the fault is applied at around $0.5 \mathrm{~s}$. A simple distance relay algorithm is implemented in Matlab, in which a $20 \mathrm{~ms}$ sliding window is used to calculate the fundamental frequency from the instantaneous values using a discrete fourier transform (DFT). The fundamental frequency data are used to determine the impedance of the fault loop using the standard formula. 
Another important aspect to consider is the components protecting the capacitor bank from overvoltage. In the simulations this overvoltage protection was shown in Figure 2, consisting of parallel branches of a metal oxide varistor (MOV) and a bypass circuit breaker (CB) with current-limiting inductance and resistance. MOVs are widely used to protect capacitors from overvoltage at the start of a fault current. Their strong nonlinearity reacts rapidly, limiting the voltage but also dissipating energy in the MOV. The bypass breaker is needed in order to avoid exceeding the MOV's protective voltage, current or energy limits. A controller determines when the bypass circuit breaker should be closed. In the simulations, this is assumed to happen $20 \mathrm{~ms}$ after reaching an operating limit. The MOV voltage and current limits are usually twice the rated capacitor voltage and current, as shown in Equations (3) and (4) where $U_{P}$ and $I_{P}$ are the MOV's protected voltage and current levels and $I_{R}$ is the capacitor's rated current. PSCAD estimates the energy accumulation in the MOV from the current and voltage across it. An energy limit is also set in the model for triggering the bypass breaker when the pre-set limit is crossed during a fault. For each compensation level used in the simulations, the MOV protection levels are adjusted to suit the chosen capacitor.

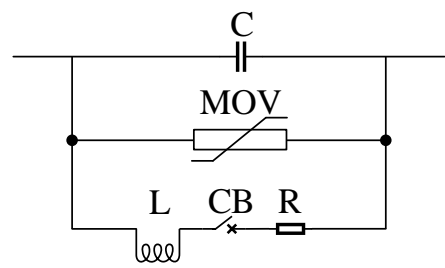

Figure 2 Capacitor overvoltage protection

$$
\begin{gathered}
U_{P}=2 \sqrt{2} I_{R} X_{C} \\
I_{P}=2 \sqrt{2} I_{R}
\end{gathered}
$$

\section{Results and Discussion}

\subsection{MOV operation}

Operation of the MOV during a fault impacts the distance protection scheme. Fault currents that are high enough to make
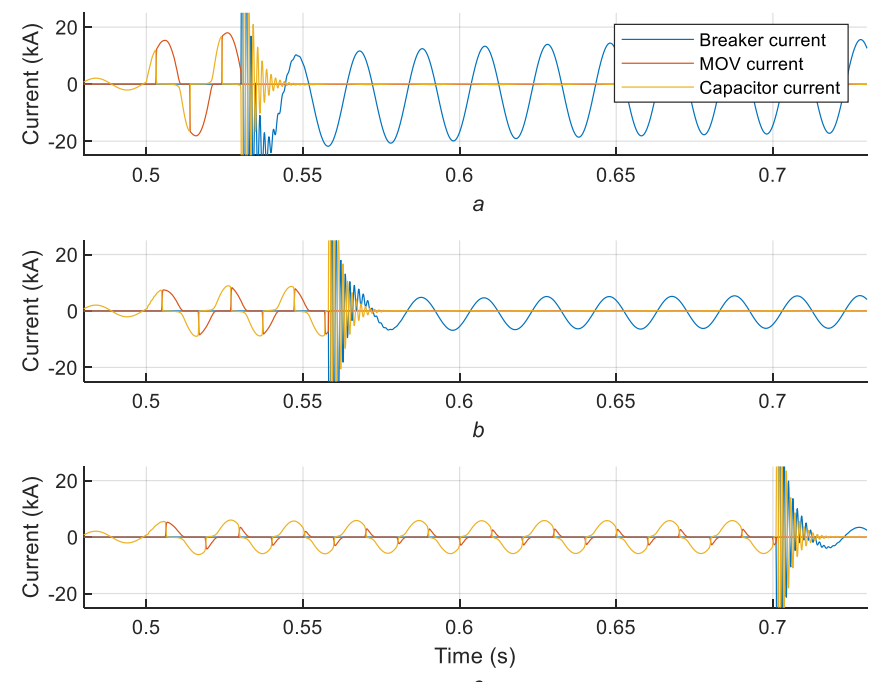

Figure 3 Capacitor, MOV and bypass CB current for (a) High current fault (b) Medium current fault (c) Low current fault the MOV conduct will be shared between the capacitor and the MOV, determined by the MOV voltage and current thresholds, capacitor value, and fault current magnitude. The sharing between these branches will vary within each cycle, as the MOV is strongly nonlinear. Closing of the bypass circuit breaker removes the compensation from the line, resulting in a linear circuit again. Figure 3 shows the MOV and bypass CB operation for three levels of fault currents. Subplot (a) shows MOV operation for a fault $10 \mathrm{~km}$ from the sending source, giving a high fault current. The MOV starts to conduct, and it closes the bypass $\mathrm{CB}$ within 1.5 cycles, taking the capacitor out of the fault loop. In subplot (b), the fault is $100 \mathrm{~km}$ from the sending end, the fault current is moderate, and the MOV control closes the CB after around 3 cycles. In subplot (c), the fault is $190 \mathrm{~km}$ from the sending end, the MOV conducts during a small part of the cycle, and after around 10 cycles the MOV energy accumulation limit is reached and the bypass CB removes the capacitor from the fault loop. Even at the highest fault current level, the MOV control takes some time to remove the capacitor from the fault loop, so it is safe to assume that it takes at least 1 cycle to remove the capacitor from the fault loop. However, in high voltage transmission lines, strict requirements are imposed on the protection system. Typical time from a fault inception to the total fault clearing by line circuit breaker is set around $100 \mathrm{~ms}$ [1]. To achieve high-speed operation of the protection system, relays need to detect fault within $0.5-1$ cycle of fault inception. Therefore, the important issue for the distance relay is the share of fault current conducted by the capacitor and MOV in the first cycle after fault inception.

\subsection{Current and Voltage Inversion}

The current and voltage inversion cause directional discrimination problems for a distance relay. The relay measures a negative phase angle and fails to recognize the fault direction. In the first cycles after the fault, the capacitive fault current due to current or voltage inversion leads to identifying a forward fault as a fault behind the relay. In Figure 4, the phase angle between line voltage and current during a fault is plotted for two fault positions and three levels of

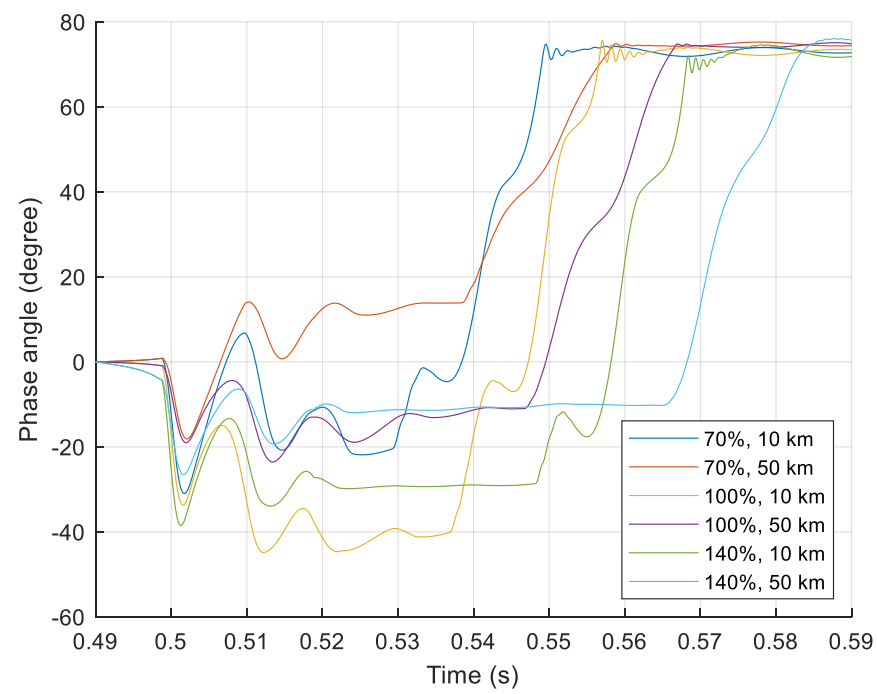

Figure 4 Evolution of measured fault impedance angle for different compensation levels, for bolted phase-ground fault 
compensation. A negative value of the phase angle indicates current or voltage inversion. With a higher compensation level the phase angle takes a longer time to return to a positive value. Also, the proportion of the line length where a fault may cause current or voltage inversion increases with increasing compensation levels. A fault at $50 \mathrm{~km}$ from the sending bus does not cause inversion for $70 \%$ compensation, but it does for $100 \%$ and $140 \%$ compensation.

\subsection{Effect of SSO}

Sub-synchronous oscillation depends on the values of source reactance, capacitive reactance and fault loop reactance. When the sum of fault loop impedance and source reactance is slightly higher than the capacitive reactance (refer to equation (2)), SSO close to and below $50 \mathrm{~Hz}$ is observed. For a particular source reactance, higher compensation levels would increase the distance at which a fault causes SSO close and below $50 \mathrm{~Hz}$. At compensation levels well above 100\%, SSO may not be significant for faults in the protected line segment; however, in those cases, faults beyond the receiving end of the line will cause significant SSO. Figure 5 shows the impedance trajectory for fault at three positions along the line for three compensation levels. The zone 1 boundary is drawn at $80 \%$ of the line length. The biggest presence of SSO can be observed for the fault at $160 \mathrm{~km}$ from the sending end, with $100 \%$ compensation. SSO is particularly problematic when it happens for a fault close to the zone boundary of the distance relay. Then the impedance trajectory can enter the zone boundary and leave it, which may cause delayed operation for the relay, or over-reach or under-reach of the zone. From (2), we can understand that when $X_{C}$ and $\left(p X_{L}+X_{S}\right)$ are close, the resonant frequency close to $50 \mathrm{~Hz}$ is generated. Higher compensation levels means high values of $X_{C}$, therefore given that source reactance is fixed, higher values of $X_{L}$ is required to generate oscillation close to $50 \mathrm{~Hz}$. So, for high levels of compensation, worse cases of SSO will be found further away from the sending end.

\subsection{Effect on distance protection}
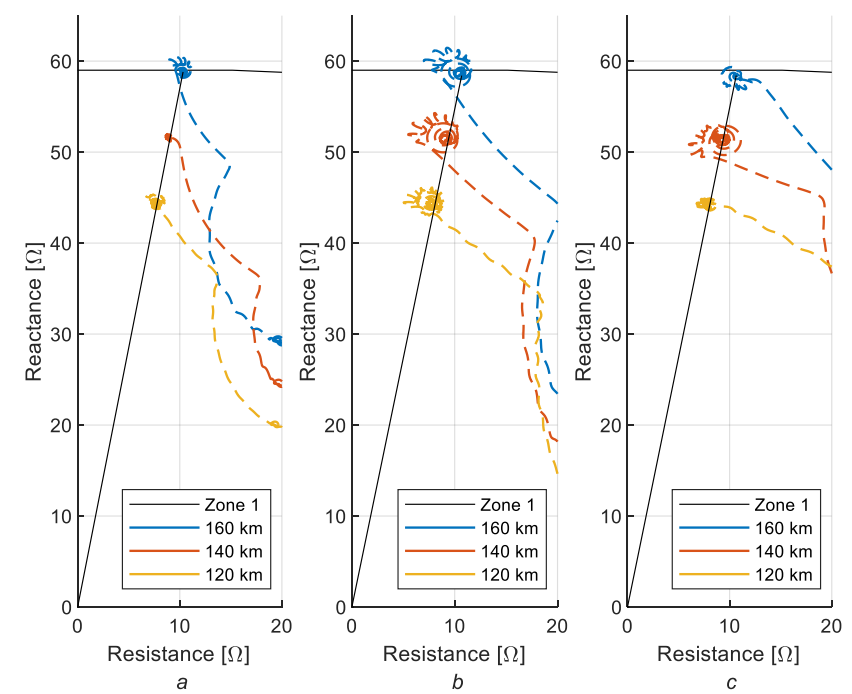

Figure 5 Impedance trajectory for faults at three levels of compensation: (a) $70 \%$ (b) $100 \%$ (c) $140 \%$
This subsection shows in the R-X plane the combined effect of MOV operation, current and voltage inversion and subsynchronous oscillation. The results are shown in Figure 6 to Figure 11, grouped by compensation level. In each figure, for each fault position, fault trajectories for two fault resistance values are shown. The dotted lines in the plot indicate the closing of the bypass breaker by the MOV controller to remove the capacitor from the fault loop. The zone boundary is set to $80 \%$ and is only indicative: in reality, zone boundaries are optimized for each line for best protection performance. The times indicated in the figure show the time required for each trajectory to enter the zone boundary and stay there for at least $5 \mathrm{~ms}$. It can be assumed this is the time it will take for a typical distance relay to issue a trip signal for that particular fault.

\subsection{1 $70 \%$ compensation:}

Figure 6 shows trajectories for a $70 \%$ compensated line with fault inception angle of $0^{\circ}$. Faults at $10 \mathrm{~km}$ from sending end because the highest delay. The fault trajectory goes through negative reactance, which indicates the presence of current or voltage inversion. The fault trajectory enters the zone boundary only after the bypass breaker is closed. For the fault at $10 \mathrm{~km}$ with $30 \Omega$ resistance, the MOV control works slower due to the lower current, and it takes an even longer time to operate. Trajectories for faults at $100 \mathrm{~km}$ move to the zone fairly quickly, so although the fault location is not determined correctly, the relay could issue a trip signal. Trajectories for faults at $190 \mathrm{~km}$ from the sending bus enter the zone boundary and remain there for a long time: in these two cases the relay may issue a trip signal even though the fault is outside the zone boundary. Fault current for the fault at $190 \mathrm{~km}$ is lower, so the capacitor remains in the fault loop for a long time and may lead to wrong operation of the relay. Figure 7 shows trajectories when the fault inception angle is changed to $90^{\circ}$. The trip times are similar to those with an inception angle of $0^{\circ}$, but the trajectories are different, for faults with different resistances.

\subsection{2 $100 \%$ compensation:}

Figure 9 shows the fault impedance trajectories for $100 \%$ compensation and fault inception angle of $0^{\circ}$. Here, faults at

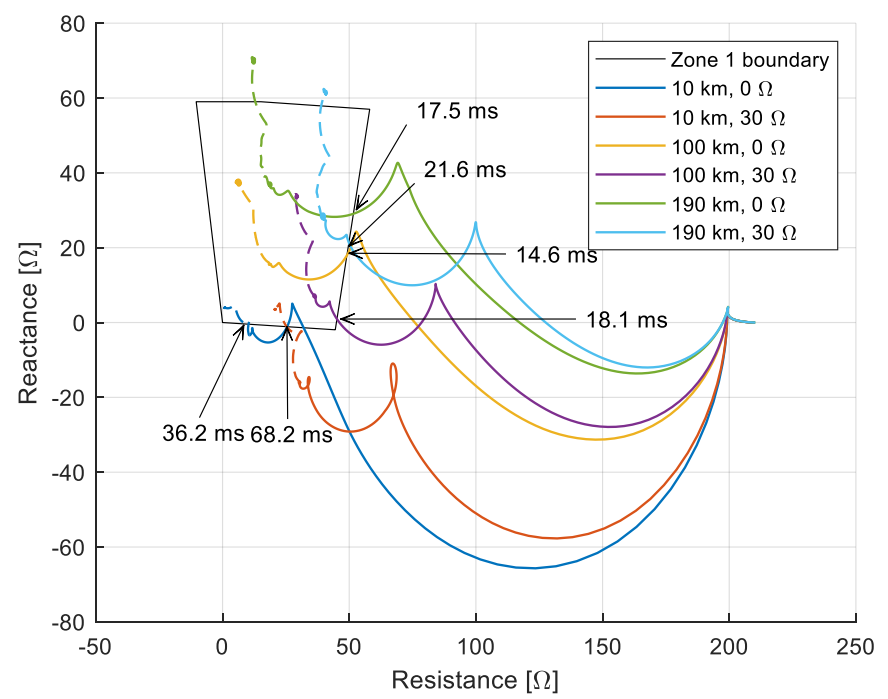

Figure $670 \%$ compensation, $0^{\circ}$ inception angle 


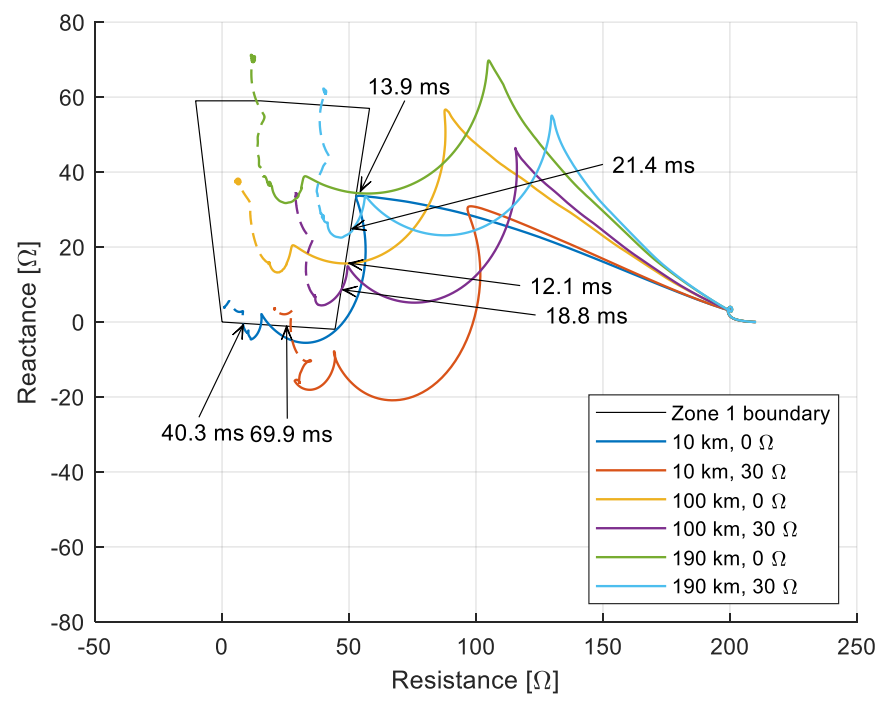

Figure $770 \%$ compensation, $90^{\circ}$ inception angle

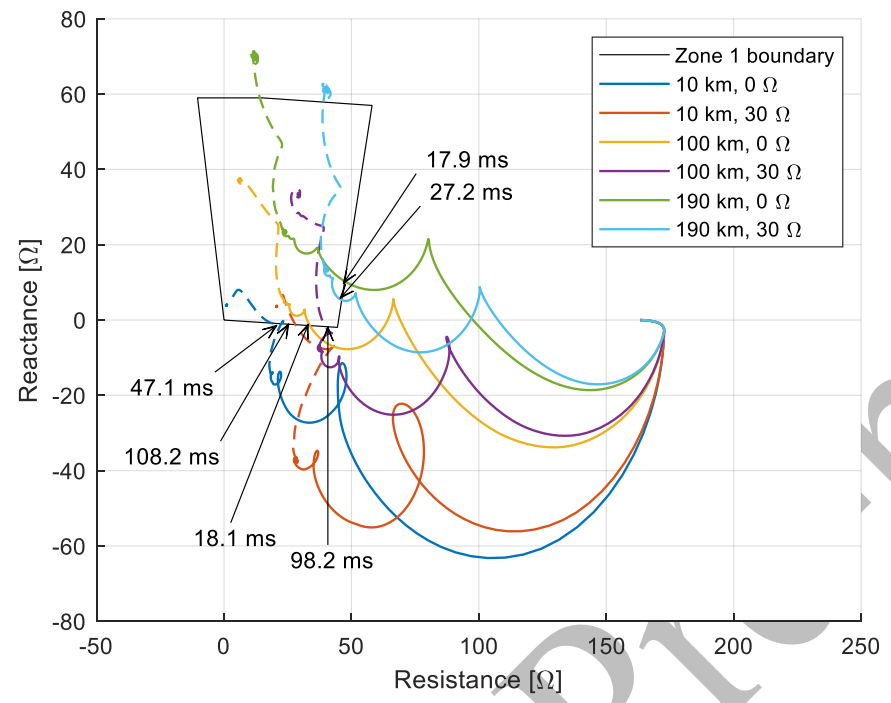

Figure $9100 \%$ compensation, $0^{\circ}$ inception angle

$10 \mathrm{~km}$ for both $0 \Omega$ and $30 \Omega$, and $100 \mathrm{~km}$ for $30 \Omega$, enter the zone boundary after the bypass breaker is closed. This causes a delay in relay operation. A fault at $100 \mathrm{~km}$ with $0 \Omega$ resistance enters the zone quickly but only settles to the right position after the bypass breaker is closed. Fault trajectories for faults at $190 \mathrm{~km}$ enter the zone boundary and stay there until the bypass breaker is closed. Some oscillations can be observed in these trajectories as well. Figure 8 shows the impedance trajectories for faults for $100 \%$ compensated line with $90^{\circ}$ fault inception angle. The trip times are slightly smaller compared to $0^{\circ}$ fault inception. Faults with $30 \Omega$ resistance $10 \mathrm{~km}$ and $100 \mathrm{~km}$ take around $100 \mathrm{~ms}$ to enter the zone boundary.

\subsubsection{0\% compensation:}

Figure 10 and Figure 11 shows impedance trajectories for $140 \%$ compensation for $0^{\circ}$ and $90^{\circ}$ fault inception angles. Faults at $10 \mathrm{~km}$ from the sending end with $0 \Omega$ and $30 \Omega$, and $100 \mathrm{~km}$ with $30 \Omega$ fault resistance, only enter the zone boundary after the bypass CB closes. A fault at $100 \mathrm{~km}$ with $0 \Omega$ fault resistance enters the zone boundary quickly. Faults at $190 \mathrm{~km}$ from sending bus with $0 \Omega$ resistance enter the zone

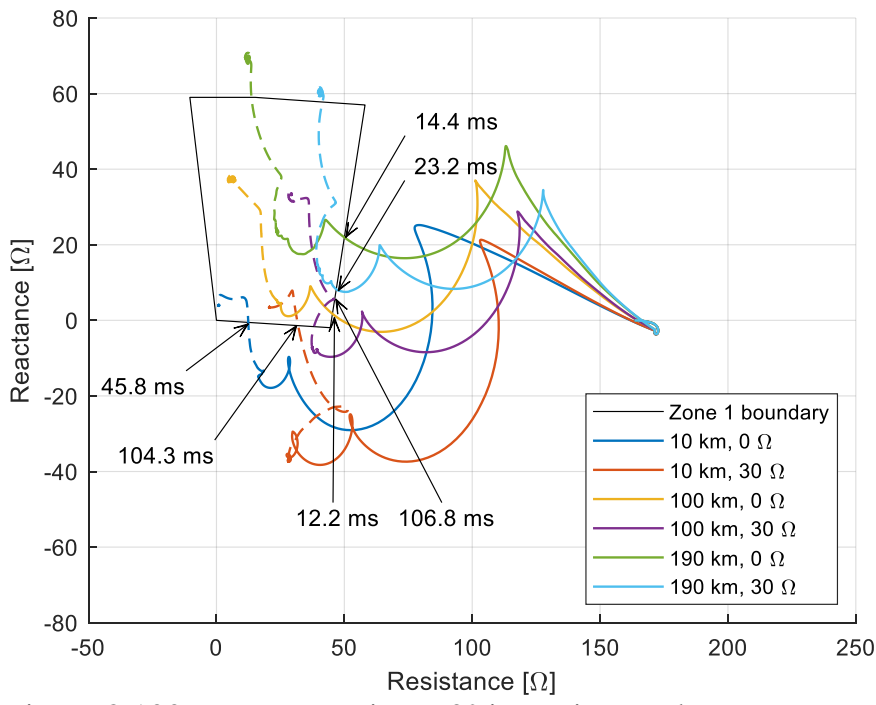

Figure $8100 \%$ compensation, $90^{\circ}$ inception angle

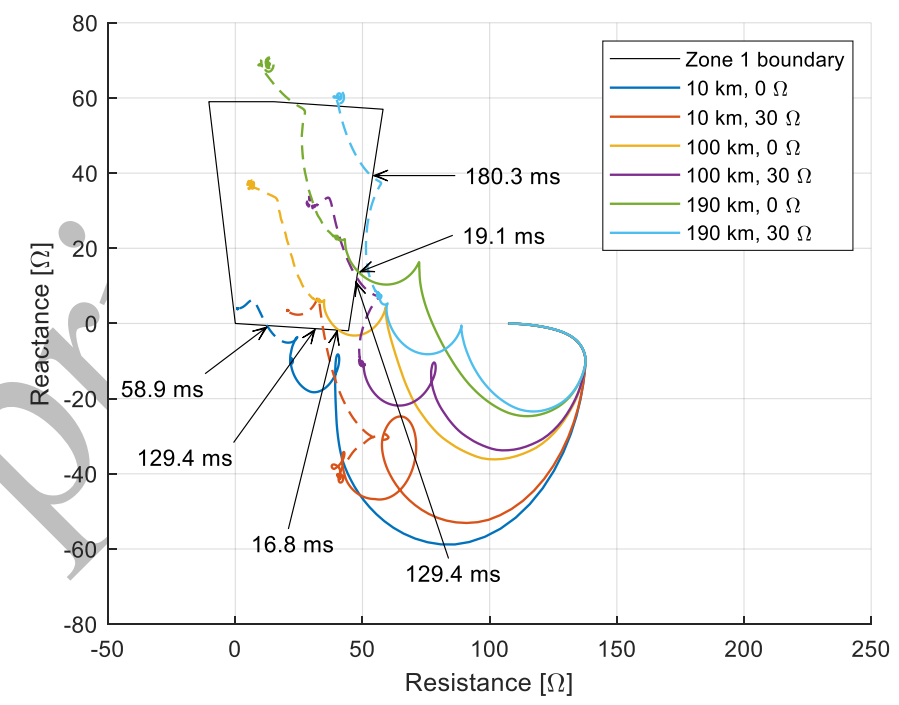

Figure $10140 \%$ compensation, $0^{\circ}$ inception angle

boundary quickly and remains there, this may cause false operation. However, faults at $190 \mathrm{~km}$ with $30 \Omega$ fault resistance take around $180 \mathrm{~ms}$ to enter the zone boundary, and leave the zone after $10 \mathrm{~ms}$. Here, for faults at $190 \mathrm{~km}$, some oscillation can be observed in the impedance trajectory. In both figures, faults at $190 \mathrm{~km}$ stays in the zone 1 until the bypass breaker closes, this can cause overreach problem.

\section{Conclusion}

In terms of our aims of understanding the impact of high levels of series compensation on existing distance protection with MOV operation, current and voltage inversion and SSO, the following conclusions have been obtained based on the simulation results:

- Current and voltage inversion increase with increasing levels of compensation, causing a delay in distance relay operation, overreach/under reach and potential directional problems.

- The line segment where a fault would generate SSO close to $50 \mathrm{~Hz}$ moves further away from the sending end with 


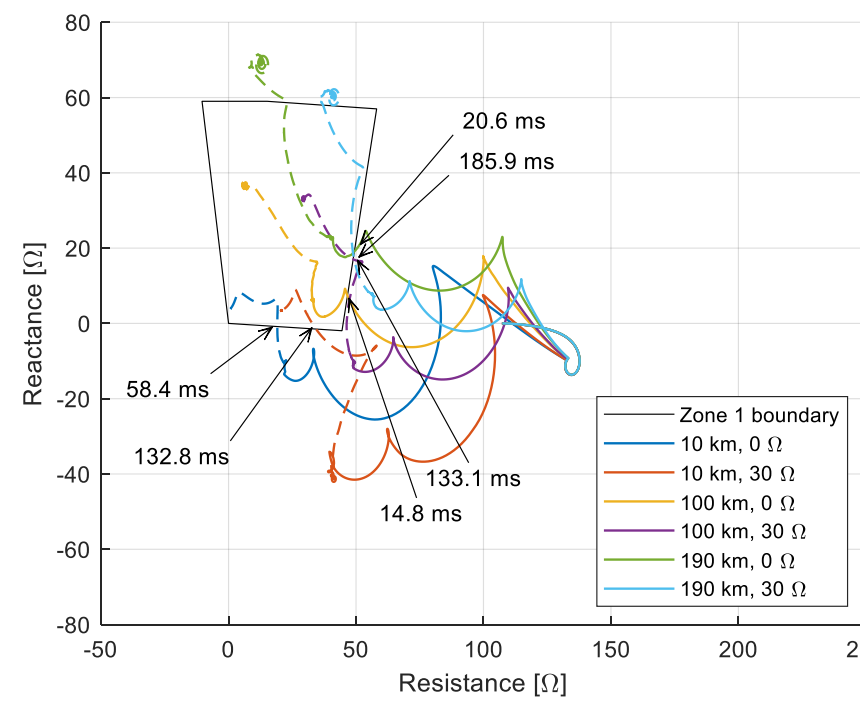

Figure $11140 \%$ compensation, $90^{\circ}$ inception angle

increasing levels of compensation. This condition has high impact on existing distance protection installed in the connected system.

- Faults close to and far away from the sending bus where the capacitor is installed are the most challenging to handle with traditional distance protection.

- $\quad \mathrm{MOV}$ and bypass breaker operation has major impact on series compensated line protection scheme.

It can be concluded that using traditional distance protection with high levels of series compensation is rather challenging. There has been research on improving distance protection for series capacitor compensated lines, but most of the studies are limited to lower compensation levels, such as 50\% and less. Those methods need to be tested for lines with high levels of compensation. For the record, if alternative solutions for the protection of series capacitor compensation lines are considered, another popular scheme that is used widely is differential protection, based on current balance at the line ends. In theory, current inversion in higher levels of series compensation may cause dependability problems (no trip when required) for the differential relays. The differential relay experiencing current inversion may identify the fault on the other side of the bus. However, differential relays will not have a security problem (false trip) in series compensated lines. These issues are discussed by the authors in a previous paper [7]. The main disadvantage of differential protection is its need of redundant communication between the protected line terminals. Another possible way forward on the protection of series capacitor compensated lines is time-domain protection schemes such as travelling wave based protection schemes. Those will be explored in further work in this project.

\section{Acknowledgement}

This work was funded through SweGRIDS, by the Swedish Energy Agency, ABB and Svenska kraftnät.

\section{References}

[1] CIGRE Working Group B5.10, "Protection, control and monitoring of series compensated networks," CIGRE, Paris, 2010.

[2] John Miller, Marc Brunet-Watson, and Jed Leighfield, "Review of Series Compensation for Transmission Lines," PSC North America, 2014.

[3] F. A. Albasri, T. S. Sidhu, and R. K. Varma, "Performance Comparison of Distance Protection Schemes for Shunt-FACTS Compensated Transmission Lines," IEEE Trans. Power Deliv., vol. 22, no. 4, pp. 2116-2125, Oct. 2007.

[4] E. Bakie, C. Westhoff, N. Fischer, and J. Bell, "Voltage and current inversion challenges when protecting seriescompensated lines - A case study," in 2016 69th Annual Conference for Protective Relay Engineers (CPRE), College Station, TX, USA, 2016, pp. 1-14.

[5] B. Kasztenny and G. Brunello, "Distance Protection of Series Compnesated Lines- Problems and Solutions," in Transmission \& Distribution Latin America Conference, Sao Paolo, Brazil, 2002, p. 36.

[6] I. T. B. Tavares, S. P. de O. Silva, and K. M. e Silva, "Parametric sensitivity analysis of series compensated transmission lines protection," in Simposio Brasileiro de Sistemas Eletricos (SBSE), 2018, pp. 1-6.

[7] M. T. Hoq, J. Wang, and N. Taylor, "The Impact of Current Inversion on Line Protection in High Voltage Transmission Lines with Series Compensation," presented at the The Conference on Energy, Power Systems and Power- and Industrial Electronics (NORPIE), 2019. 